\title{
Taxonomic Position of Korean Isolates of Rhizoctonia solani Based on RAPD and ITS Sequencing of Ribosomal DNA
}

\author{
Young-Ah Jeon ${ }^{2}$, Wan-Gyu Kim¹, Dae-Ho Kim², Soon-Wo Kwon² and Seung-Beom Hong ${ }^{2 *}$ \\ ${ }^{1}$ Korean Agricultural Culture Collection of National Agrobiodiversity Center and Agricultural Microbiology Division \\ ${ }^{2}$ National Academy of Agricultural Science, RDA, Suwon 441-707, Korea \\ (Received on June 24, 2009; Accepted on January 13, 2010)
}

\begin{abstract}
Taxonomic position of 46 Korean isolates of Rhizoctonia solani which were classified into nine intraspecific groups by anastomosis and cultural characteristics was analyzed by randomly amplified polymorphic DNA (RAPD) and sequence analyses of the internal transcribed spacer (ITS) regions of ribosomal DNA. All the isolates within each group showed highly similar band patterns in RAPD. The ITS regions of the isolates within the same groups showed a high level of sequence similarity above $\mathbf{9 6 . 0 \%}$ whereas similarities among different groups were below 94.4\%. When compared with several reference strains of $R$. solani from foreign countries, all the Korean isolates were clustered with the foreign isolates belonging to the same groups in the phylogenetic tree. All six Korean strains of AG-4 were identified as HG-1 out of 3 subgroup of AG-4. We discussed taxonomic position of Korean isolates of $R$. solani and showed that sequence analysis with ITS regions could be a rapid and useful method for identification of intraspecific group of R. solani.
\end{abstract}

Keywords : anastomosis, ITS, randomly amplified polymorphic DNA, Rhizoctonia solani

Rhizoctonia solani Kühn [teleomorph: Thanatephorus cucumeris (Frank) Donk], the most recognized species within genus Rhizoctonia, is potent pathogen of economically important plant species and shows considerable diversity in morphology, geographic location, host specificity and pathogenicity (Ogoshi, 1987). Kim et al. (1994; 1995) reported that $R$. solani had caused 65 diseases to wide range of plants including rice, potato, pepper, vegetables, ornamentals, turf grasses, pine tree etc. in Korea. The concept of anastomosis group (AG) is a widely accepted principle for identifying intraspecific groups in the $R$. solani complex (Carling, 1996). Fourteen AGs, AG-1 through AG-13 and AG-BI (bridging isolates), had been described for $R$. solani by this concept (Carling, 1996; Ogoshi, 1987). However,

\footnotetext{
*Corresponding author.

Phone) +82-31-299-1866, FAX) +82-31-299-1869

E-mail) funguy@korea.kr
}

AG concept is not an ideal method for classification of $R$. solani as misidentification is caused from the varied frequency of hyphal fusion in some AG (Liu and Sinclair, 1992).

For the biological bases of $\mathrm{AG}$, vitamin requirement analysis (Ogoshi and Ui, 1979), serological studies (Adams and Butler, 1979), fatty acid analyses (Stevens Johnk and Jones, 1993; Stevens Johnk et al., 1993), isozyme analyses (Reynolds et al., 1983), total soluble protein pattern (Liu and Ge, 1988), GC content analysis and DNA-DNA hybridization (Kuninaga and Yokozawa, 1980) had been studied. Recently, molecular biological techniques have been used in combination with morphological and physiological markers for the analysis of $R$. solani population (Guleria et al., 2007). The restriction fragment length polymorphism (RFLP) studies on ribosomal DNA regions were performed to differentiate AGs and their subgroups (O'Brien, 1994; Vilgalys and Gonzales, 1990). Randomly amplified polymorphic DNA PCR (RAPD-PCR) analysis was performed to detect genetic variability among the isolates of $R$. solani (Sharma et al., 2005). Sequence analyses of the internal transcribed spacer (ITS) regions of ribosomal DNA have been used to study the genetic relationships between AGs of $R$. solani by many authors (Boysen et al., 1996; Gonzales et al., 2001; Kuninaga et al., 1997; 2000; Salazar et al., 1999).

Several studies were performed with Korean isolates of the species. Kim et al. (1994; 1995) reported cultural characteristics of $R$. solani isolates collected from various crop plants in Korea and Hong et al. (1998) performed PCR-RFLP analysis of their partial 18S-ITS-5.8S region of ribosomal DNA. However, there has been no report on the taxonomic position of Korean isolates using sequence analysis of ribosomal ITS region. In this study, we examined genetic diversity of 46 Korean isolates of $R$. solani, representing 9 groups ( 6 anastomosis group and 5 cultural types) using randomly amplified polymorphic DNA (RAPD) and DNA sequences of ribosomal ITS region. The objectives of this study were to: (1) determine the complete DNA sequence of the ribosomal ITS regions of Korean isolates, (2) confirm the relatedness between molecular 
evidences and previous identification by anastomosis and cultural characteristics, and (3) examine the taxonomic position of Korean isolates within $R$. solani complex.

Forty-six Rhizoctonia solani isolates, representing 6 anastomosis groups (AGs) and 5 cultural types (CTs), were used in this study (Table 1). For RAPD analysis, PELF(5'-ATA TCA TCG AAG CCG C-3') and URP1F (5'-ATC CAA GGT CCG AGA CAA CC-3') by Kang et al. (2002) were used. Ribosomal ITS region was amplified with ITS1 (5'-TTC GTA GGT GAA CCT GCG G-3')

Table 1. The isolates of Rhizoctonia solani used in this study

\begin{tabular}{|c|c|c|c|c|c|}
\hline Isolate no. & AG, subgroup & Host & Origin & $\begin{array}{l}\text { Sequence } \\
\text { accession no.* }\end{array}$ & Reference \\
\hline KACC 40101 & AG-1, IA & Oryza sativa & Korea & KA004124 & This study \\
\hline KACC 40102 & AG-1, IA & Zea mays & Korea & KA004125 & This study \\
\hline KACC 40103 & AG-1, IA & Arachis hypogaea & Korea & KA004126 & This study \\
\hline KACC 40104 & AG-1, IA & Cyperus exaltatus var. iwasakii & Korea & KA004127 & This study \\
\hline KACC 40106 & AG-1, IA & Oryza sativa & Korea & KA004129 & This study \\
\hline A-10 & AG-1, IA & Oryza sativa & Japan & $\mathrm{AB} 000010$ & Kuninaga et al. (1997) \\
\hline KACC 40107 & AG-1, IB & Codonopsis lanceolata & Korea & KA004130 & This study \\
\hline KACC 40108 & AG-1, IB & Lactuca sativa & Korea & KA004131 & This study \\
\hline KACC 40109 & AG-1, IB & Cucurbita moschata & Korea & KA004132 & This study \\
\hline KACC 40110 & AG-1, IB & Nicotiana tabacum & Korea & KA004133 & This study \\
\hline KACC 40111 & AG-1, IB & Cucumis sativus & Korea & KA004134 & This study \\
\hline KACC 40112 & AG-1, IB & Lactuca sativa & Korea & KA004135 & This study \\
\hline $001-7$ & AG-1, IB & Soil & Japan & $\mathrm{AB} 000025$ & Kuninaga et al. (1997) \\
\hline KACC 40113 & AG-1, IC & Brassica campestris ssp. pekinensis & Korea & KA004136 & This study \\
\hline KACC 40115 & AG-1, IC & Chaenomeles sinensis & Korea & KA004137 & This study \\
\hline KACC 40116 & AG-1, IC & Soil & Korea & KA004138 & This study \\
\hline KACC 40117 & AG-1, IC & Brassica oleracea var. capitata & Korea & KA004139 & This study \\
\hline KACC 40118 & AG-1, IC & Soil & Korea & KA004140 & This study \\
\hline PS-1 & AG-1, IC & Beta vulgaris & Japan & AB000029 & Kuninaga et al. (1997) \\
\hline $3 \mathrm{Rs}$ & AG-1, IC & Pinus densiflora & Canada & AF354058 & Gonzalea et al. (2001) \\
\hline KACC 40119 & AG-2-1 & Brassica campestris ssp. pekinensis & Korea & KA004162 & This study \\
\hline KACC 40120 & AG-2-1 & Lactuca sativa & Korea & KA005649 & This study \\
\hline KACC 40121 & AG-2-1 & Tulipa gesneriana & Korea & KA005650 & This study \\
\hline KACC 40122 & AG-2-1 & Malva verticillata & Korea & KA004141 & This study \\
\hline KACC 40123 & AG-2-1 & Panax ginseng & Korea & KA004163 & This study \\
\hline KACC 40124 & AG-2-1 & Raphanus sativus & Korea & KA005651 & This study \\
\hline $\mathrm{R} 123$ & AG-2-1 & Brassica oleracea var. capitata & Japan & AB000030 & Kuninaga et al. (1997) \\
\hline $8 \mathrm{Rs}$ & AG-2-1 & Soil & Australia & AF354063 & Gonzalea et al. (2001) \\
\hline KACC 40125 & AG-2-2, IIIB & Platycodon grandiflorum & Korea & KA004142 & This study \\
\hline KACC 40126 & AG-2-2, IIIB & Angelica gigas & Korea & KA005652 & This study \\
\hline KACC 40127 & AG-2-2, IIIB & Citrullus lanatus & Korea & KA005653 & This study \\
\hline KACC 40128 & AG-2-2, IIIB & Citrullus lanatus & Korea & KA004164 & This study \\
\hline KACC 40129 & AG-2-2, IIIB & Cyperus exaltatus var. iwasakii & Korea & KA005654 & This study \\
\hline KACC 40130 & AG-2-2, IIIB & Zingiber officinale & Korea & KA005655 & This study \\
\hline $\mathrm{C}-96$ & AG-2-2, IIIB & Juncus effusus & Japan & AB054854 & Carling et al. (2002) \\
\hline KACC 40131 & AG-2-2, IV & Daucus carota var. sativa & Korea & KA004165 & This study \\
\hline KACC 40133 & AG-2-2, IV & Gypsophila elegans & Korea & KA004143 & This study \\
\hline KACC 40134 & AG-2-2, IV & Angelica gigas & Korea & KA005656 & This study \\
\hline KACC 40135 & AG-2-2, IV & Daucus carota var. sativa & Korea & KA005657 & This study \\
\hline BC-10 & AG-2-2, IV & Beta vulgaris & Japan & AB000014 & Kuninaga et al. (1997) \\
\hline RI-64 & AG-2-2, IV & Beta vulgaris & Brazil & AY270014 & \\
\hline
\end{tabular}


Table 1. Continued

\begin{tabular}{|c|c|c|c|c|c|}
\hline Isolate no. & AG, subgroup & Host & Origin & $\begin{array}{l}\text { Sequence } \\
\text { accession no.* }\end{array}$ & Reference \\
\hline $48 \mathrm{R}$ & AG-2-2, LP & Zoysia tennuifolia & Japan & AB054866 & Carling et al. (2002) \\
\hline RGR38 & AG-2-2, LP & Cynodon dactylon & Japan & AB054869 & Carling et al. (2002) \\
\hline H5-307 & AG-2-3 & Glycine $\max$ & Japan & AB054870 & Carling et al. (2002) \\
\hline LB17-3-2 & AG-2-3 & Glycine max & Japan & AB054872 & Carling et al. (2002) \\
\hline $758 \mathrm{C}$ & AG-2-4 & Dauscus carota & USA & AB054879 & Carling et al. (2002) \\
\hline KACC 40136 & AG-3 & Solanum tuberosum & Korea & KA004166 & This study \\
\hline KACC 40137 & AG-3 & Solanum tuberosum & Korea & KA004144 & This study \\
\hline KACC 40138 & AG-3 & Solanum tuberosum & Korea & KA004145 & This study \\
\hline 1600 & AG-3 & Nicotiana tabacum & USA & AB000004 & Kuninaga et al. (1997) \\
\hline $1600 \mathrm{NC}$ & AG-3 & Nicotiana tabacum & USA & AF153774 & Pope \& Carter (2001) \\
\hline FL3 & AG-3 & Nicotiana tabacum & USA & AF153773 & Pope \& Carter (2001) \\
\hline OKA-6 & AG-3 & Lycopersicon esculentum & Japan & AB000023 & Kuninaga et al. (1997) \\
\hline ST3-1 & AG-3 & Solanum tuberosum & Japan & AB000041 & Kuninaga et al. (1997) \\
\hline $\mathrm{CP} 245$ & AG-3 & Solanum tuberosum & USA & AF153771 & Pope \& Carter (2001) \\
\hline $\mathrm{K} 213 \mathrm{C}$ & AG-3 & Solanum tuberosum & Russia & AF153772 & Pope \& Carter (2001) \\
\hline $\mathrm{T} 31$ & AG-3 & Solanum tuberosum & Spain & AY387528 & \\
\hline CBS 211.84 & AG-3 & Solanum tuberosum & Netherlands & AY387574 & \\
\hline KACC 40139 & AG-4, HG-I & Raphanus sativus & Korea & KA004146 & This study \\
\hline KACC 40140 & AG-4, HG-I & Cucumis sativus & Korea & KA005658 & This study \\
\hline KACC 40141 & AG-4, HG-I & Capsicum annuum & Korea & KA005659 & This study \\
\hline KACC 40142 & AG-4, HG-I & Cucumis melo & Korea & KA004147 & This study \\
\hline KACC 40143 & AG-4, HG-I & Dianthus caryophillus & Korea & KA004148 & This study \\
\hline KACC 40144 & AG-4, HG-I & Spinacia oleracea & Korea & KA004149 & This study \\
\hline $78-23 R-3$ & AG-4, HG-I & Spinacia oleracea & Japan & AB000007 & Kuninaga et al. (1997) \\
\hline R97 & AG-4, HG-I & Beta vulgaris & Japan & AB000031 & Kuninaga et al. (1997) \\
\hline Chr-3 & AG-4, HG-I & Chrysanthemum morifolium & Japan & AB000015 & Kuninaga et al. (1997) \\
\hline Rh-131 & AG-4, HG-II & Beta vulgaris & Japan & AB000031 & Kuninaga et al. (1997) \\
\hline $7 \mathrm{Rs}$ & AG-4, HG-II & Medicago sativa & USA & AF354074 & Gonzalea et al. (2001) \\
\hline $18 \mathrm{Rs}$ & AG-4, HG-II & Beta vulgaris & Japan & AF354072 & Gonzalea et al. (2001) \\
\hline $6 \mathrm{Rs}$ & AG-4, HG-III & Conifer & USA & AF354077 & Gonzalea et al. (2001) \\
\hline $45 \mathrm{Rs}$ & AG-4, HG-III & Beta vulgaris & USA & AF354076 & Gonzalea et al. (2001) \\
\hline KACC 40145 & AG-5 & Allium fistulosum & Korea & KA004150 & This study \\
\hline KACC 40146 & AG-5 & Panax ginseng & Korea & KA004151 & This study \\
\hline KACC 40147 & AG-5 & Iris nerpschinskia & Korea & KA004152 & This study \\
\hline KACC 40148 & AG-5 & Zingiber officinale & Korea & KA005660 & This study \\
\hline KACC 40150 & AG-5 & Brassica oleracea var. capitata & Korea & KA005661 & This study \\
\hline K31 & AG-5 & Pine tree & Japan & AB000021 & Kuninaga et al. (1997) \\
\hline
\end{tabular}

*The sequence accession numbers, KAxxxxxx, of ribosomal ITS regions were from Korean Agricultural Culture Collection (KACC, http:// kacc.rda.go.kr), and the other numbers from GenBank of NCBI.

and ITS4 (5'-AAC ATG CGT GAG ATT GTA AGT-3') primers (White et al., 1990) and sequenced in Solgent co. Ltd. The ITS sequences aligned by Clustal W (Thompson et al., 1994) and, phylogenetic tree was constructed using MEGA version 4 (Tamura et al., 2007) with reference sequences from GenBank and sequence of Rhizoctonia alpina (CBS 309.35) was used as an outgroup. Distances were calculated using the Tamura-Nei parameter model and a phylogenetic tree was constructed through Neighbor-Joining (NJ) analysis. Bootstrap analysis was performed with 1,000 re-samples of data.

Interrelation between intraspecific groups and molecular characteristics. Forty-six Rhizoctonia solani isolates 
were analyzed by RAPD using two primers, PELF and URP1F and both primers produced multiple polymorphic bands. Although there were some differences in minor bands, isolates in the same AG showed the identical band patterns (Fig. 1). The length of ribosomal ITS regions varied as AGs due to various length of ITS1 (198-237 bp) and ITS2 (269-289 bp). Except for two subgroups of AG-2-2, sequence similarities of the Korean isolates were above $98.7 \%$ in the same groups but below 94.4\% among the different groups. Phylogenetic analysis using ITS region with 730 bp length including gaps showed that isolates belonging to the different groups formed completely distinct clusters. When compared with 32 reference isolates from foreign countries listed in Table 1, all the Korean isolates were well clustered with them by AGs (Fig. 2). Isolates of three subgroups of AG-1 clustered with reference isolates of each subgroups. Four subgroups of AG-2 were phylogenetically distant each other and AG-2-1 and AG-2-4 made a cluster with AG-3, however, AG-2-2 and AG-2-3 made a cluster with AG-5. All isolates of three subgroups of AG-2-2 were well clustered according to their group although the cluster of AG-2-2(IV) had low bootstrap value. Three Korean isolates of AG-3 from potato were much closer to reference isolates from potatoes than those from tobacco and tomato. All the Korean isolates of AG-4 were closed to HG-I among three subgroups of AG-4. Molecular characteristics examined by RAPD analysis and ITS sequencing were strongly interrelated with intraspecific groups by cultural characteristics and anastomosis.

Taxonomic position of Korean isolates within $R$. solani complex. AG-1 was divided into three subgroups based on pathogenicity and cultural characteristics. They were AG1(IA) causing sheath blight on rice, AG-1(IB) causing webblight and AG1(IC) causing damping off in host plants (Sneh et al., 1991). Our result from sequence analysis of ribosomal ITS region and RAPD showed that the three subgroups were completely distinguishable from each other. This result was consistent with previous report showing the different PCR-RFLP band patterns of $17 \mathrm{~S}$ and ITS regions digested by a restriction enzyme Cfr 13I (Hong et al., 1998).

AG-2 causing root disease on crucifer (Anderson, 1982) had been divided into five subgroups, AG-2-1, AG-2-2, AG-2-3, AG-2-4 and AG-2(BI), on the basis of hyphal fusion frequency (Carling et al., 2002; Ogoshi, 1987). Isolates of AG-2-1 are autotrophic, and isolates of AG-2-2 and AG-2-3 are auxotrophic for thiamine. AG-2-2 is subdivided again into two cultural types, AG-2-2(IIIB) (rush type) and AG-2-2(IV) (root rot type) on the basis of their pathogenicity on mat rush and sugar beet, respectively (Salazar et al., 1999), and confirmed by analyses of DNA sequence homology (Liu and Sinclair, 1992). In the present study, we examined 16 Korean isolates of AG-2-1, AG-2-2(IIIB), and AG-2-2(IV). Six strains of AG-2-1 were located near to AG-2-4 and AG-3. However, 6 strains of AG-2-2 (IIIB) and 4 strains of AG-2-2 (IV) were located near to AF-2-3 and AG-2-5 (Fig. 2). It means that AG-2 is not monophyletic. Further physiological and phylogenetical study would be required to understand AG-2. Traditionally, field isolates of AG-3 had been considered to be main pathogens causing stem canker, stolon lesion, and black sclerotia on tubers of potato (Anderson, 1982). However, Date et al. (1984) and Stevens Johnk et al.

\section{(A) PELF}

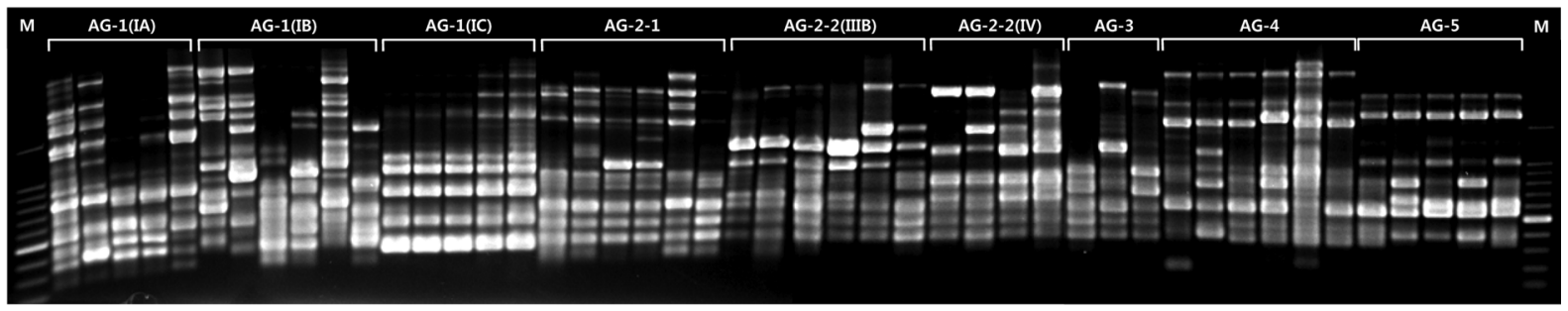

\section{(B) URP1F}

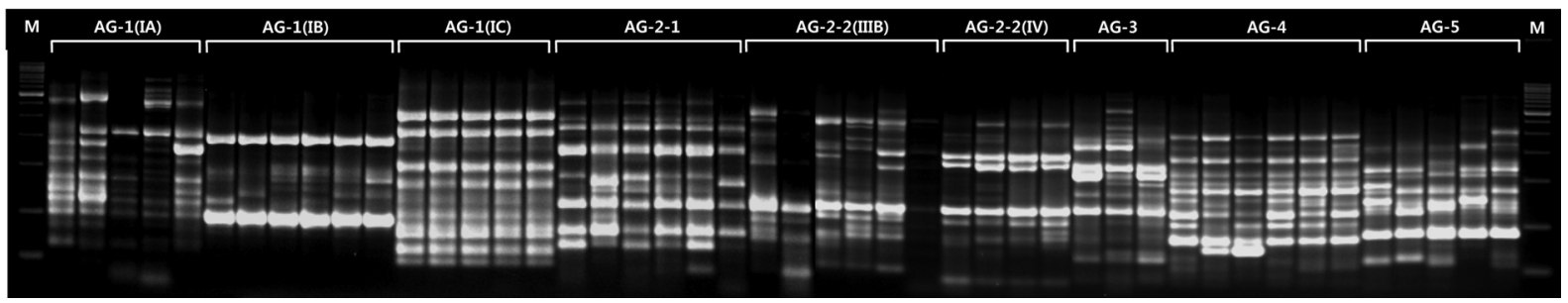

Fig. 1. RAPD band pattern of the Korean isolates of Rhizoctonia solani generated by PELF and URP1F primers. The texts above the lanes represent intraspecific groups. 


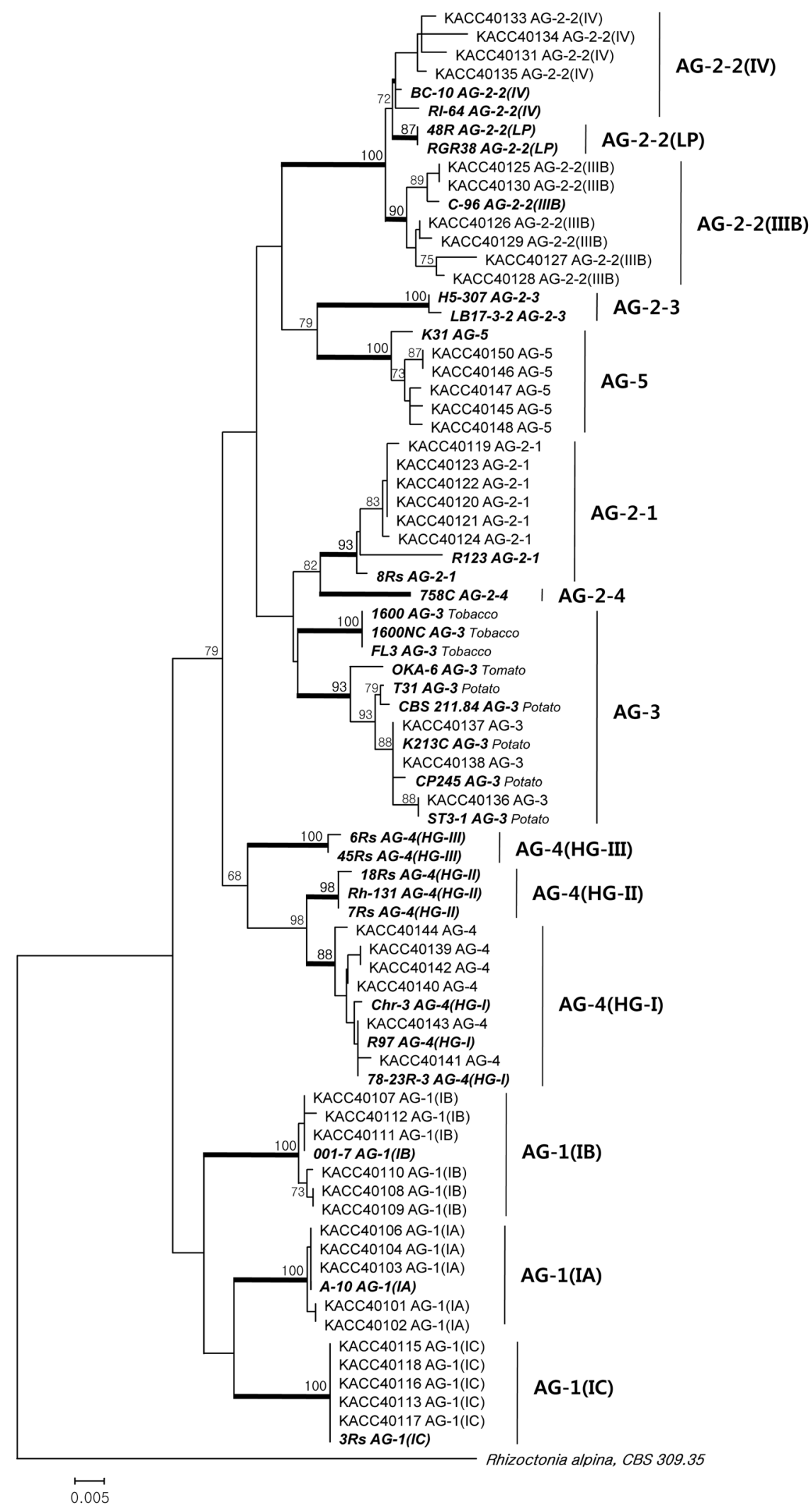

Fig. 2. Neighbor-Joining tree of the Korean isolates of $R$. solani with reference isolates (in bold) based on the sequence of ribosomal ITS region. The numbers above or below the nodes represent bootstrap values of $>60 \%$ (out of 1,000 bootstrap replication). The number of nucleotide changes is represented by branch length. CBS 309.35 (R. alpina) was used as outgroup. 
(1993) reported that isolates of AG-3 caused leaf blight of tomato and target spot of tobacco, respectively. Several authors reported previously differences in fatty acid, isozyme composition, sequence variation of ribosomal ITS region and pathogenicity between AG-3 isolates originated from tobacco and potato (Carling and Leiner, 1990; Kuninaga et al., 2000; Stevens Johnk et al., 1993). Three Korean isolates of AG-3 originated from potato were completely clustered with reference isolates from potato, but located distantly from those from tobacco.

Several studies suggested that AG-4 may consist of three homogeneous subgroups, HG-I, HG-II and HG-III, by biochemical and molecular evidences such as fatty acid analysis (Stevens Johnk and Jones, 2001), DNA-DNA reassociation (Kuninaga and Yokozawa, 1984) and nucleotide sequence analysis of ribosomal ITS region (Kuninaga et al., 1997). Based on the sequence of ITS, all Korean isolates of AG-4 were clustered into HG-I. However, any relatedness between subgroups and host plants was not observed. Five isolates of AG-5 were well clustered with reference strain from overseas. This group showed close relationships with AG-2-3.

According to Ogoshi (1987), R. solani shows considerable diversity in geographic location and host specificity. However, we did not observe significant relatedness among the sequences of ribosomal ITS region and isolated location in this study. Almost Korean and overseas isolates in the same groups showed high sequence similarity in ribosomal ITS regions. Only AG-3 isolates showed a trend of host specificity in phylogenetic tree with ITS sequences.

For identification of AG and cultural type in R. solani, we have usually performed anastomosis test with reference strains from every recognized group and examined their cultural and morphological characteristics. However, it is not easy work because we have to collect reference strains from every group and anstomosis test takes long time and the results are often ambiguous to determine. According to results from this work, ribosomal ITS region was strongly discriminative to AGs of $R$. solani complex. Almost Korean isolates of $R$. solani were classified into nine intraspecific groups by anastomosis and cultural characteristics, and they were well clustered to their reference isolates from overseas in phylogenetic tree with ITS sequences. It means that sequence analysis with ribosomal ITS regions could be a good and rapid method to identify anastomosis groups and cultural types in $R$. solani complex.

\section{References}

Adams, G. C. Jr. and Butler, E. E. 1979. Serological relationships among anastomosis groups of Rhizoctonia solani. Phytopa- thology 69:629-633.

Anderson, N. A. 1982. The genetics and pathology of Rhizoctonia solani. Ann. Rev. Phytopathol. 20:329-347.

Boysen, M., Borja, M., del Moral, C., Salazar, O. and Rubio, V. 1996. Identification at strain level of Rhizoctonia solani AG-4 isolates by direct sequence of asymmetric PCR products of the ITS regions. Curr. Genet. 29:174-181.

Carling, D. E. 1996. Grouping in Rhizoctonia solani by hyphal anastomosis reaction. In: Sneh et al. (eds) Rhizoctonia species: taxonomy, molecular biology, ecology, pathology and disease control. Kluwer Academic Publishers, Dordrecht, The Netherlands, pp. 37-47.

Carling, D. E. and Leiner, R. H. 1990. Virulence of isolates of Rhizoctonia solani AG-3 collected from potato plant organs and soil. Plant Dis. 74:901-903.

Carling, D. E., Kuninaga, S. and Brainard, K. A. 2002. Hyphal anastomosis reactions, rDNA-internal transcribed spacer sequences, and virulence levels among subsets of Rhizoctonia solani AG 2 and AG BI. Phytopathology 92:43-50.

Date, H., Yagi, S., Okamoto, Y. and Onili, N. 1984. On the leaf blight of tomatoes Thanatephorus cucumeris (Frank) Donk (Rhizoctonia solani). Ann. Phytopathol. Soc. Jpn. 50:339.

Gonzalez, D., Carling, E. D., Kuninaga, S., Vilgalys, R. and Cubeta, M. A. 2001. Riobosomal DNA sysmatics of Ceratobasidium and Thanatephorus with Rhizoctonia anamorphs. Mycologia 93:1138-1150.

Guleria, S., Aggarwal, R., Thind, T. S. and Sharma, T. R. 2007. Morphological and pathological variability in rice isolates of Rhizoctonia solani and molecular analysis of their genetic variability. J. Phytopathol. 155:654-661.

Hong, S. B., Go, S. J., Ryu, J. C., Kim, W. G. and Kim, I. S. 1998. Differentiation of intraspecific groups within Korean isolates of Rhizoctonia solani using PCR-RFLP of ribosomal DNA. Kor. J. Plant Pathol. 14:157-163 (In Korean).

Kang, H. W., Park, D. S. and Eun, M. Y. 2002. Fingerprinting of diverse genomes using PCR with universal rice primers generated from repetitive sequence of Korean weedy rice. Mol. Cells 13:281-287.

Kim, W. G., Cho, W. D. and Lee, Y. H. 1994. Anastomosis groups and cultural characteristics of Rhizoctonia solani isolates from crops in Korea. Kor. J. Mycol. 22:309-324.

Kim, W. G., Cho, W. D. and Ryu, H. Y. 1995. Diagnosis and control of Rhizoctonia diseases on crops. Research Report RDA.

Kuninaga, S., Natsuaki, T., Takeuchi, T. and Yokosawa, R. 1997. Sequence variation of the rDNA ITS regions within and between anastomosis groups in Rhizoctonia solani, Curr. Genet. 32:237-243.

Kuninaga, S., Carling, D. E., Takeuchi, T. and Yokosawa, R. 2000. Comparison of rDNA-ITS sequences between potato and tobacco strains in Rhizoctonia solani AG-3. J. Gen. Plant Pathol. 66:2-11.

Kuninaga, S. and Yokosawa, R. 1980. A comparison of DNA base compositions among anastomosis groups in Rhizoctonia solani Khn. Ann. Phytopathol. Sco. Jpn. 46:150-158.

Kuninaga, S. and Yokosawa, R. 1984. DNA base sequence homology in Rhizoctonia solani Khn. IV. Genetic relatedness 
within AG-4. Ann. Phytopathol. Sco. Jpn. 50:322-330.

Liu, Z. L. and Sinclair, J. B. 1992. Genetic diversity of Rhizoctonia solani anastomosis group 2. Phytopathology 82:778-787.

Liu, Z. L. and Ge, Q. X. 1988. Studies on soluble protein patterns of Rhizoctonia solani by polyacrylamide gel electrophoresis. I. The influence of different source of isolates on protein patterns of anastomosis group. Acta Mycol. Sin. 7:175-182.

O'Brien, P. A. 1994. Molecular markers in Australian isolate of Rhizoctonia solani. Mycol. Res. 98:665-671.

Ogoshi, A. and Ui, T. 1979. Specific vitamin requirement among anastomosis groups of Rhizoctonia solani Khn. Ann Phytopathol. Soc. Jpn. 45:47-53.

Ogoshi, A. 1987. Ecology and pathogenicity of anastomosis and intraspecific groups of Rhizoctonia solani Khn. Annu. Rev. Phytopathol. 25:125-143.

Pope, E. J. and Carter, D. A. 2001. Phylogenetic placement and host specificity of mycirrhizal isolates belonging to AG-6 and AG-12 in the Rhizoctonia solani species complex. Mycologia 93:712-719.

Reynolds, M., Weinhold, A. R. and Moris, T. J. 1983. Comparison of anastomosis groups of Rhizoctonia solani by polyacrylamide gel electophoresis of soluble proteins. Phytopathology 73:903-906.

Salazar, O., Schneider, J. H. M., Julian, M. C., Keijer, J. and Rubio, V. 1999. Phylogenetic subgrouping of Rhizoctonia solani AG 2 isolates based on ribosomal ITS sequences. Mycologia 91:459-467.

Sharma, M., Gupta, S. K. and Sharma, T. R. 2005. Characterization of variability in Rhizoctonia solani by using morphological and molecular markers. J. Phytopathol. 153:449-456.
Sneh, B., Burpee, L. and Ogoshi, A. 1991. Identification of Rhizoctonia species. APS Press, St. Paul, MN., USA. pp. 133.

Stevens Johnk, J. and Jones, R. K. 2001. Differentiation of three homogeneous groups of Rhizoctonia solani anastomosis group 4 by analysis of fatty acids. Phytopathology 91:821830.

Stevens Johnk, J. and Jones, R. K. 1993. Differentiation of populations of AG-2-2 of Rhizoctonia solani by analysis of fatty acids. Phytopathology 83:278-283.

Stevens Johnk, J., Jones, R. K., Shew, H. D. and Carling, D. E. 1993. Characterization of populations of Rhizoctonia solani AG-3 from potato and tobacco. Phytopathol. 83:854-858.

Tamura, K., Dudley, J., Nei, M. and Kumar, S. 2007. MEGA4: Molecular Evolutionary Genetics Analysis (MEGA) software version 4.0. Mol. Biol. Evol. 24:1596-1599.

Thompson, J. D., Higgins, D. G. and Gibson, T. J. 1994. CLUSTAL W: Improving the sensitivity of progressive multiple sequence alignment through sequence weighting, position specific gap penalties and weight matrix choice. Nucl. Acids Res. 22:46734680.

Vilgalys, R. and Gonzales, D. 1990. Ribosomal DNA restriction fragment length polymorphisms in Rhizoctonia solani. Phytopathology 80:151-158.

White, T. J., Bruns, T. D., Lee, S. and Taylor, J. W. 1990. Amplification and direct sequencing of fungal ribosomal RNA genes for phylogenetics. In: PCR Protocols: A guide to methods and applications, eds. by M. A. Innis, D. H. Gelfand, J. J. Sinsky and T. J. White, pp. 315-322. Academic Press, New York, USA. 